\title{
Transcription by RNA polymerase II induces changes of DNA topology in yeast
}

\author{
Brian I. Osborne and Leonard Guarente \\ Massachusetts Institute of Technology, Department of Biology, Cambridge, Massachusetts 02139 USA
}

\begin{abstract}
We show that induction of transcription of a CYC1-lacZ fusion gene, borne on a yeast plasmid, causes an increase in negative superhelicity of approximately five turns. This increase is abolished by deletion of either essential element of the CYC1 promoter, the upstream activation site (UAS), or the TATA boxes. Several experiments indicate that the size of the increase is proportional to the size of the transcribed region. First, an internal deletion removing half of the CYC1-lacZ transcribed region results in a plasmid whose negative superhelicity on induction is intermediate between promoter-deletion plasmids and the parental plasmid. Second, plasmids bearing insertions of a fragment containing the putative CYC1 terminator into the CYC1$l a c Z$ fusion gene have relative negative superhelicities proportional to the length of the truncated fusion transcripts generated. A plausible model explaining these observations is that local unwinding of the double helix by transcribing RNA polymerase generates positively supercoiled DNA, which is subsequently relaxed by a topoisomerase.
\end{abstract}

[Key Words: RNA polymerase II transcription; negative supercoiling; transcription termination]

Received January 21, 1988; revised version accepted April 18, 1988.

DNA isolated from many different organisms has been found to be underwound or negatively supercoiled. In Escherichia coli, the extent of negative supercoiling is controlled by the opposing activities of the type I topoisomerases and DNA gyrase. Although gyrase introduces negative supercoils, the type I topoisomerases tend to relax negative supercoils (Wang 1985). Another possible source of negative superhelicity is suggested by experiments in vitro. Wang et al. (1977) showed that negative supercoils were introduced into a nicked plasmid by the unwinding of the double helix by RNA polymerase in the presence of DNA ligase. In the same manner, the combined action of in vitro transcription by RNA polymerase and topoisomerase introduced negative supercoils into a closed, circular DNA. The transcription of DNA by RNA polymerase unwound the helix, introducing positive supercoils. Relaxation of the positively supercoiled DNA by topoisomerase resulted in a net decrease in linking number, i.e., an increase in negative superhelicity (Gamper and Hearst 1982).

In eukaryotes, the mechanism by which negatively supercoiled DNA is generated is less clear. In principle, the negative supercoiling found in deproteinized, episomal DNA could be attributed to the wrapping of DNA into nucleosomes in vivo. Topoisomerases have been identified in all eukaryotes examined, ranging from yeast to mammals. However, although these enzymes will relax supercoiled DNA, they will not introduce negative supercoils like $E$. coli DNA gyrase. In yeast, two genes, TOP1 and TOP2, have been shown to encode topoisomerases (Goto and Wang 1984, 1985; Thrash et al. 1985; Uemura and Yanagida 1986), and these enzymes have been implicated in several critical cellular events.
The product of the TOP2 gene was first shown to be required to decatenate newly replicated $2 \mu$ DNA (DiNardo et al. 1984). Because the TOP2 gene product was shown to act in the $M$ phase of the cell cycle and top2 mutant cells could not segregate their chromosomes properly, it was inferred that the enzyme is also required for decatenation of newly replicated yeast chromosomes (Holm et al. 1985; Uemura and Yanagida 1986).

Although eukaryotic topoisomerases have been implicated directly in replication, their role in transcription is less certain. Experiments in Drosophila have demonstrated a physical association of topoisomerase I with transcribed DNA (for review, see Wang 1985). In Saccharomyces, the presence of either the TOP1 or TOP2 products was shown to be needed for transcription of the rDNA repeats by RNA polymerase I but not for transcription of the GAL1 gene (Brill et al. 1987). Thus, these experiments do not link a topoisomerase to RNA polymerase II transcription. It is possible that the block to rDNA transcription operates at the level of initiation at the rDNA promoter. In $E$. coli, topoisomerase mutations have been shown to alter the activities of numerous promoters (for review, see Gellert 1981; Sternglanz et al. 1981). It is also possible, as proposed, that topoisomerases act as swivels to relieve positive torsional stress generated by transcription within the rDNA cluster (Brill et al. 1987). Such stress would be due to unwinding of the DNA by the transcriptional machinery.

In this paper, we show a link between topoisomerase action and transcription by RNA polymerase II. We demonstrate that induction of transcription of a CYC1lacZ gene results in an increase of negative supercoiling of a plasmid in Saccharomyces cerevisiae. This increase 
is abolished by deleting the CYC1 UAS or TATA boxes and is intermediate in plasmids containing shortened transcripts. One means by which shortened transcripts are generated is by insertion of the CYC1 terminator into the CYC1-lacZ gene. Our results are discussed in terms of a model proposing that unwinding of the template by transcribing RNA polymerase creates torsional stress that is adjusted by the action of a topoisomerase.

\section{Results}

A system to detect transcriptionally induced changes in supercoiling

We sought to devise a system to maximize the chance of detecting changes in supercoiling induced by transcription. A simple method to separate topoisomers of a plasmid is gel electrophoresis in the presence of an intercalator, such as chloroquine. By this means, a supercoiled plasmid will be displayed as a distribution of topoisomers that differ, one from the next, by one superhelical turn (or a difference of one in linking number). The most intense band at the center of a distribution denotes the average superhelical density. The plasmid LG-312 (Guarente and Mason 1983) has several features that make it suitable for a study of transcriptionally induced changes of supercoiling in yeast (Fig. 3a). First, the plasmid contains a highly regulated promoter, that of the CYC1 gene of yeast. Second, induction is expected to result in a substantial increase in the number of RNA polymerases transcribing from the plasmid. This increase is expected because the induced CYC1 promoter is fairly strong and because the transcript initiated at this promoter is relatively long, covering $7 \mathrm{~kb}$ of the plasmid before ending at the distal end of the Amp ( $\beta$-lactamase) gene. The remaining $4 \mathrm{~kb}$ of the plasmid is taken up by the URA3 gene and an untranscribed segment bearing the $2 \mu$ origin of replication (Broach 1981). We reasoned that the increase in the number of RNA polymerase molecules on the plasmid after induction could result in a detectable increase in negative supercoiling, as observed for $E$. coli RNA polymerase in vitro (Wang et al. 1977; Gamper and Hearst 1982).

\section{Analysis of supercoiling in repressing and inducing conditions}

Cells bearing pLG-312 were grown in conditions in which the CYC1 promoter is repressed (in glucose medium), or fully induced (in lactate medium). DNA was isolated from cells, phenol extracted, electrophoresed in the presence of two different concentrations of chloroquine, and transferred to nylon. The topoisomers were revealed by hybridization to an internal lac $Z$ fragment. As shown in Figure 1, the topoisomers from the induced cells migrated faster than the topoisomers from the repressed cells. Because an increase in the concentration of chloroquine, which decreases negative supercoiling, slowed the migration of topoisomers (Fig. 1b), it follows that the faster migrating topoisomers are more negatively supercoiled.
This result alone does not rule out the possibility that the difference in the linking number of pLG-312 is an indirect consequence of growth in glucose or lactate media and is not related to transcription of the CYC1lac $Z$ gene. That this is not the case is suggested by the observation that the endogenous $2 \mu$ plasmid, or pLG-312 derivatives that are deleted for essential CYC1 promoter
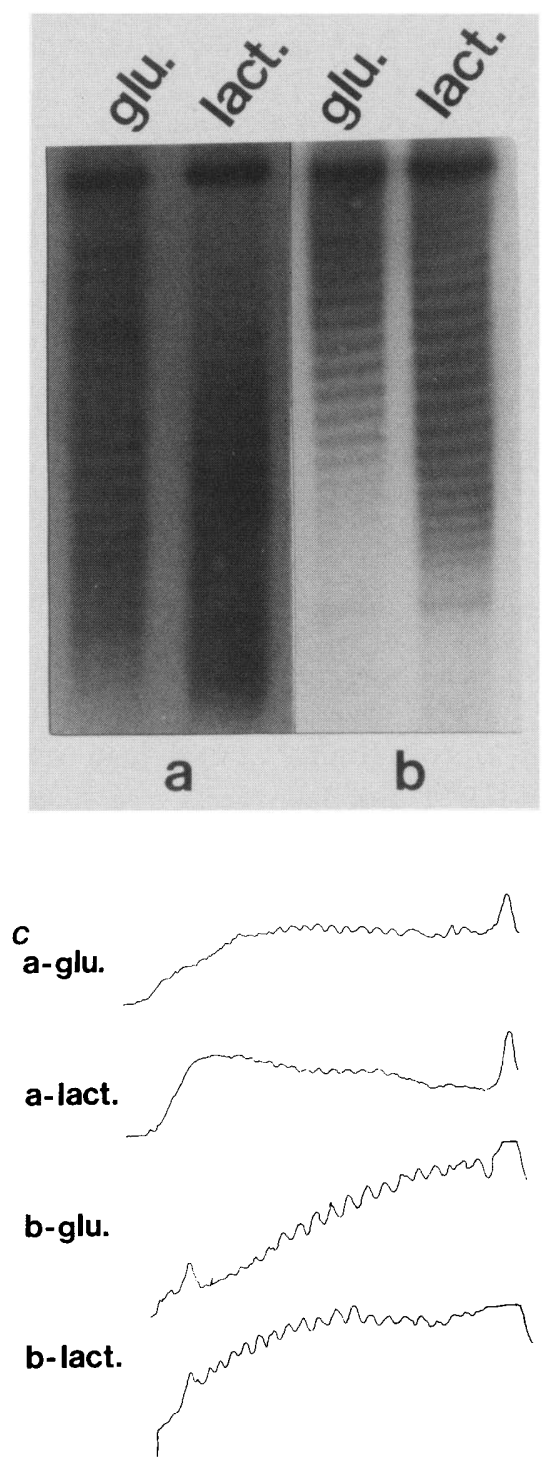

Figure 1. Southern analysis of DNA from cells transformed with plasmids bearing repressed or induced $C Y C 1-l a c Z$ fusion genes. DNA was prepared from BWG1-7a transformed with pLG-312, electrophoresed in chloroquine gels, and blotted as described in Materials and methods. The band at the bottom of the distribution in this and subsequent figures is linear $2 \mu$ plasmid DNA. (a) DNA from transformants grown in repressing (glucose) or inducing (lactate) medium, electrophoresed in the presence of $2 \mu \mathrm{g} / \mathrm{ml}$ of chloroquine. $(b)$ DNA from transformants grown in repressing (glucose) or inducing (lactate) medium, electrophoresed in the presence of $4 \mu \mathrm{g} / \mathrm{ml}$. of chloroquine. (c) Densitometric tracings of topoisomers shown in $a$ and $b$. 
promoter elements (Guarente and Mason 1983), have the same superhelical density in glucose and lactate media (data not shown).

\section{Effects of promoter deletions on supercoiling}

If the increase in negative supercoiling of pLG-312 were a direct consequence of transcription, deletion of essential elements of the CYC1 promoter should prevent the increase. In Figure 2, we show that deletion of either the CYC1 UAS or the TATA region, both of which are essential for transcription of the gene (Guarente and Mason 1983), abolished the increase in negative superhelicity in inducing conditions. A densitometric scan of this autoradiogram indicates that the difference in linking number due to the CYC1 UAS is about five turns.

\section{Effects of alterations in the size of the transcribed region on supercoiling}

We wished to investigate whether altering the size of the CYC1-lacZ transcriptional unit would exert a corresponding effect on the change in supercoiling. We describe two approaches that shorten the transcriptional unit, internal deletion and employment of the putative CYC1 terminator. In the first approach, an internal fragment of $4 \mathrm{~kb}$ was deleted from the $7-\mathrm{kb}$ transcriptional unit. To recreate a plasmid of the same size and sequence as pLG-312, this fragment was inserted into an untranscribed region on the plasmid (Fig, 3a; Broach 1981). As shown in Figure 2, the rearranged plasmid $\mathrm{pBT}+\mathrm{B}$ has a superhelical density upon induction that is intermediate between pLG-312 and the derivatives bearing promoter deletions.

In the second approach, we employed an 83-bp DNA fragment that includes sequences necessary for 3 '-end formation of the convergently transcribed CYC1 and UTR1 genes (Fig. 3b; Zaret and Sherman 1982). It was first necessary to demonstrate that this small fragment was capable of specifying 3 '-end formation. Accordingly, the fragment was cloned into three different sites in the CYC1-lacZ gene, 0.1 (BamHI), 2.0 (SacI), and 4.0 (TthIl11) kb from the promoter (see Fig. 3a). The Northern gel in Figure 4 shows that in either orientation at the SacI or TthI111 sites, the inserted fragment generated truncated transcripts of the expected sizes and prevented any read-through transcription. However, at the BamHI site, the fragment was functional in only one orientation, the $\mathrm{CYCl}(\mathrm{C})$ orientation. We think that our inability to detect the truncated transcript in this case was due to its small size, $\sim 150$ bases, but we cannot rule out the remote possibility that the fragment destabilizes a transcript that reads-through with detectable efficiency. In the UTR 1 (U) orientation, full-length CYC1$l a c Z$ message was seen at normal levels. We do not know why the fragment allowed read through in this particular construction. It is possible that the sequence TATAAA, present on the coding strand twice in this ori- entation, can act in concert with the CYC1 UAS to generate new start sites downstream.

Next, we examined the superhelical density of these constructions taken from cells grown in inducing condi-
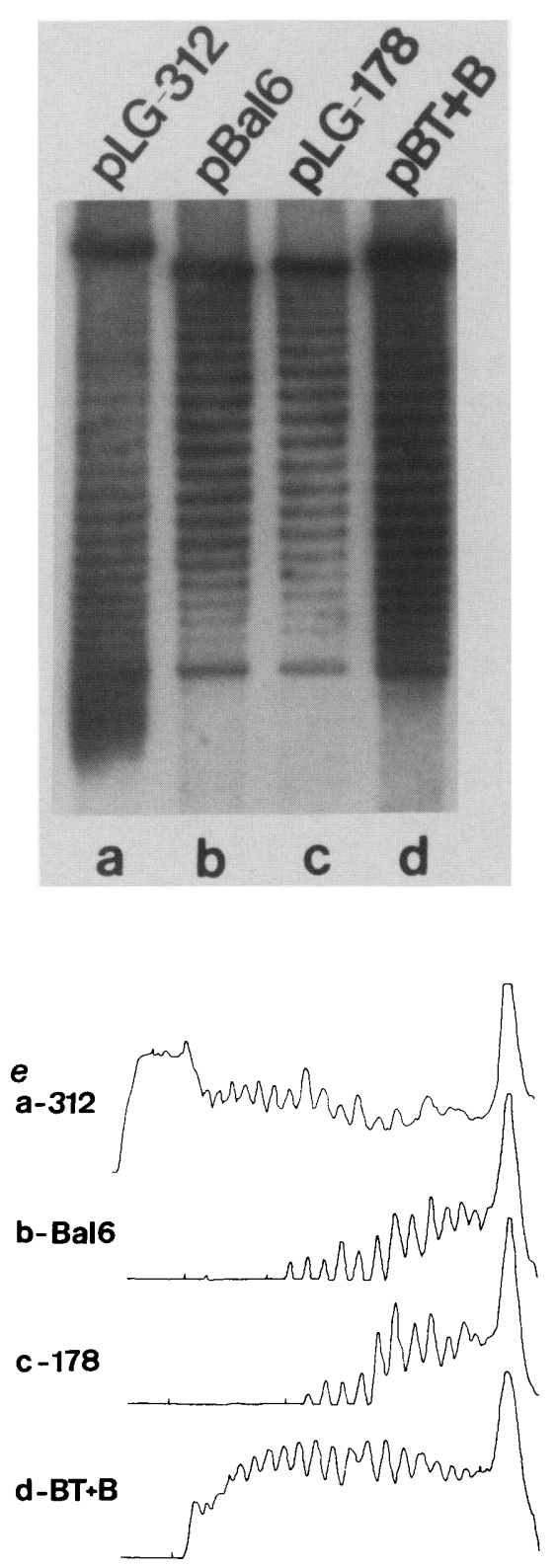

Figure 2. Southern analysis of DNA from cells transformed with plasmids bearing intact, promoter-deleted, and internally deleted CYC1-lacZ fusion genes. DNA was prepared from BWG1-7a transformants grown in inducing conditions, electrophoresed in a chloroquine gel, and blotted as described in Materials and methods. (a) DNA from cells transformed with pLG-312, which bears an intact $C Y C 1-1 a c Z$ fusion gene. $|b|$ DNA from cells transformed with pBal6, which deletes the TATA boxes from the CYC1-lacZ fusion gene. (c) DNA from cells transformed with pLG-178, which deletes both UAS1 and UAS2 from the CYC1-lacZ fusion gene. $(d)$ DNA from cells transformed with $\mathrm{pBT}+\mathrm{B}$, which deletes $4 \mathrm{~kb}$ from the $7-\mathrm{kb}$ CYC1-lacZ-transcribed region (see Fig. 3). (e) Densitometric tracings of topoisomers shown in $a-d$. 
a)
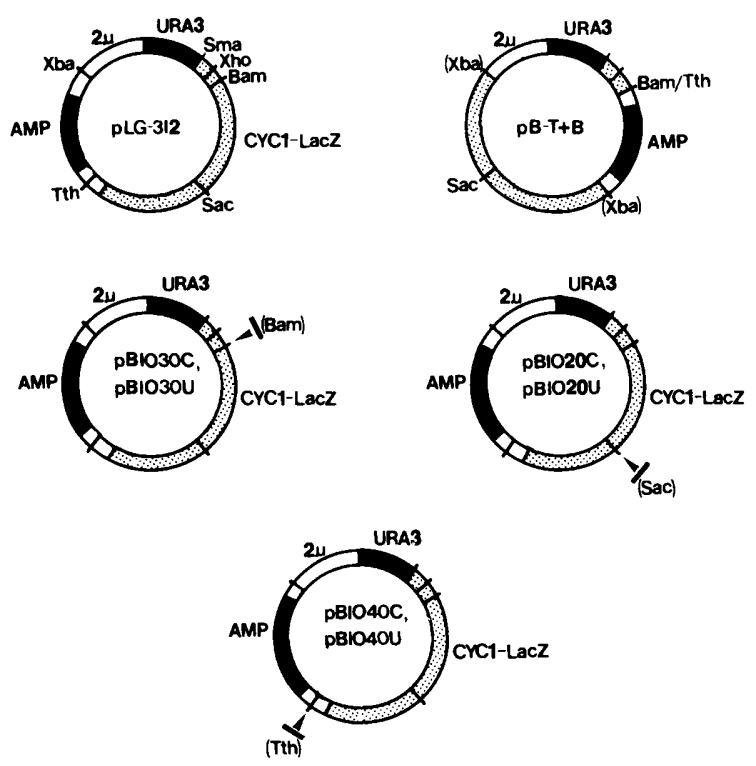

b)

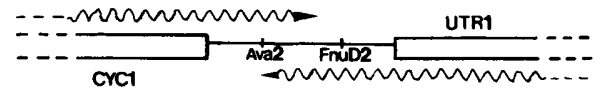

Figure 3. Diagram of the parental plasmid pLG-312, the plasmid $\mathrm{BT}+\mathrm{B}$ with an internally deleted $\mathrm{CYC1}-\mathrm{lacZ}$ fusion gene, and plasmids BI02OC, BI02OU, BI03OC, BI03OU, $\mathrm{BIO4OC}$, and $\mathrm{BIO4OU}$, which bear insertions of a putative terminator from the $3^{\prime}$ end of $C Y C 1$ into the CYC1-lacZ fusion gene. (a) Plasmid LG-312 bears the parental CYC1-lacZ fusion gene. In $\mathrm{pBT}+\mathrm{B}$, the $4-\mathrm{kb}$ BamHI-TthIl111 fragment is taken out of the 7-kb CYC1-lacZ transcribed region, leaving the promoter intact, and inserted back into the untranscribed $2 \mu$ region of the plasmid at $\mathrm{XbaI}$. Plasmids BI03OC, BI03OU, $\mathrm{BIO2OC}, \mathrm{BIO2OU}, \mathrm{BIO4OC}$, and BIO4OU are insertions of the 83-bp AvaII-FnuDII CYC1 fragment into the BamHI, SacI, or TthI1111 sites of pLG-312. The letters C (CYC1) and U (UTR1) denote the two possible orientations of the fragment, as in $b . \mid(b)$ The putative terminator is an 83 -bp AvaII-FnuDII fragment lying between the convergently transcribed CYC1 and UTR1 genes. Sequences on this fragment are necessary for 3 '-end formation of the CYC1 and UTR1 mRNAs (Zaret and Sherman 1982).

tions. In the results shown in Figure 5, it is clear that the insertion of the fragment altered the superhelical density of the plasmids. At the BamHI site, $0.1 \mathrm{~kb}$ from the promoter, the fragment in the $C$ orientation gave rise to a plasmid with a superhelical density equivalent to that of a plasmid with a promoter deletion (Fig. 2). In the U orientation, the fragment did not alter the superhelical density compared with the parent pLG-312. At the SacI $(2.0 \mathrm{~kb})$ or TthIl11 (4.0 kb) sites, in either orientation, insertions of the fragment resulted in plasmids with superhelical densities that were intermediate and varied in relation to the length of the transcripts that the inserts generated. These results are consistent with those ob- tained with the internally deleted construct and suggest that the 83 -bp fragment is a true transcriptional terminator.

\section{Discussion}

In this paper we have shown that induction of a CYC1lacZ fusion caused an increase of approximately five negative superhelical turns in the plasmid bearing the gene. This increase depended on transcription because it was abolished in plasmids deleted for essential promoter elements, either the CYC1 UAS or TATA region. Furthermore, the size of the increase in negative superhelicity was proportional to the length of the CYC1-lacZ transcript: An internal deletion of $4 \mathrm{~kb}$ of the $7-\mathrm{kb}$ transcriptional unit resulted in a reduced change in DNA superhelicity. Insertion of a putative yeast terminator into the transcribed sequences resulted in a relative superhelical shift that increased with the distance from the site of insertion to the promoter.

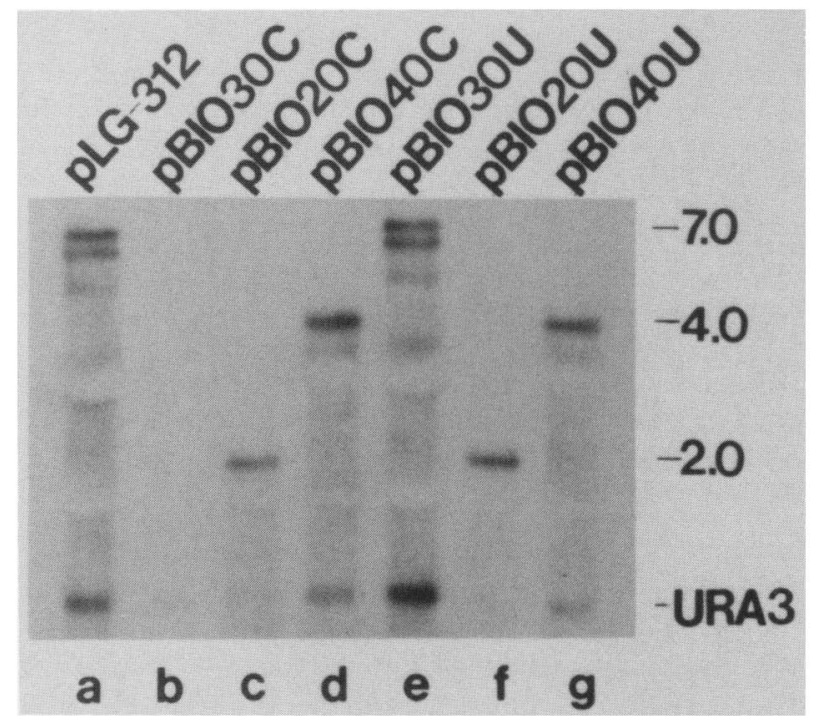

Figure 4. Northern analysis of RNA from cells transformed with plasmids bearing insertions of a putative terminator into the CYC1-lacZ fusion gene. RNA was isolated from BWG1-7a transformants grown in inducing conditions, electrophoresed, and blotted as described in Materials and methods. (a) RNA from cells transformed with pLG-312, the parental plasmid, which produces CYC1-lacZ mRNAs with an average length of $7 \mathrm{~kb}$. (b) RNA from cells transformed with BI03OC, where the putative terminator is inserted $100 \mathrm{bp}$ from the CYC1 promoter $(B a m H I)$ in the CYC1 orientation. (c) RNA from cells transformed with BI02OC, where the putative terminator is inserted $2.0 \mathrm{~kb}$ from the CYC1 promoter (SacI) in the CYC1 orientation. (d) RNA from cells transformed with BI04OC, where the putative terminator is inserted $4.0 \mathrm{~kb}$ from the CYC1 promoter (TthI1111) in the CYC1 orientation. (e) RNA from cells transformed with BIO3OU, where the putative terminator is inserted 100 bp from the CYC1 promoter (BamHI) in the UTR1 orientation. (f) RNA from cells transformed with BIO2OU, where the putative terminator is inserted $2.0 \mathrm{~kb}$ from the $C Y C 1$ promoter (SacI) in the IJTR1 orientation. (g) RNA from cells transformed with BIO4OU, where the putative terminator is inserted $4.0 \mathrm{~kb}$ from the CYC1 promoter (TthI1111) in the UTR1 orientation. 


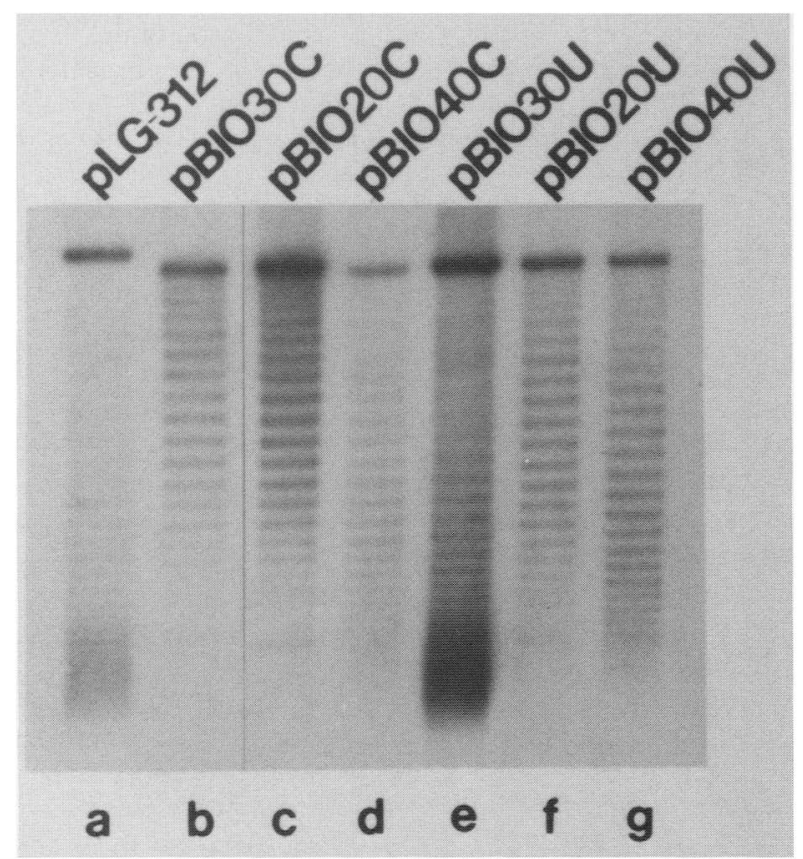

Figure 5. Southern analysis of DNA from cells transformed with plasmids with insertions of a putative terminator into the CYC1-lacZ fusion gene. DNA was prepared from BWG1-7a transformants grown in inducing conditions, electrophoresed in a chloroquine gel, and blotted as described in Materials and methods. (a) DNA from cells transformed with pLG-312, which bears an intact $C Y C 1-$ lacZ fusion gene. (b) DNA from cells transformed with $\mathrm{BIO3OC}$, where the putative terminator is inserted $100 \mathrm{bp}$ from the CYC1 promoter (BamHI) in the CYC1 orientation. (c) DNA from cells transformed with BI02OC, where the putative terminator is inserted $2.0 \mathrm{~kb}$ from the $C Y C 1$ promoter (SacI) in the CYC1 orientation. (d) DNA from cells transformed with $\mathrm{BIO4OC}$, where the putative terminator is inserted $4.0 \mathrm{~kb}$ from the CYC1 promoter (TthI111) in the CYC1 orientation. (e) DNA from cells transformed with BI03OU, where the putative terminator is inserted $100 \mathrm{bp}$ from the CYC1 promoter (BamHI) in the UTR1 orientation. $(f)$ DNA from cells transformed with $\mathrm{BIO2OU}$, where the putative terminator is inserted $2.0 \mathrm{~kb}$ from the CYC1 promoter ( $\mathrm{SaCI})$ in the UTR1 orientation. $(g)$ DNA from cells transformed with $\mathrm{BI04OU}$, where the putative terminator is inserted $4.0 \mathrm{~kb}$ from the CYC1 promoter (TthI111) in the UTR1 orientation.

\section{The relationship between transcription and superhelical density}

Although our results provide a link between transcription by RNA polymerase II and topoisomerase, we cannot be certain of the mechanism that generates the increase in negative supercoils. If transcription of CYC1-lacZ had effects on replication or chromosome structure, indirect changes in supercoiling could result. It is unlikely that the observed changes in superhelicity result from a disruption of nucleosomes, however, because such an alteration would increase supercoiling in the positive direction.

A clue as to mechanism may be provided by the relationship between the size of the transcribed region and the magnitude of the increase in negative supercoils. We suggest that the transcriptionally induced increase in negative superhelicity results from an increase in the number of RNA polymerase molecules within a transcription unit. On induction, the local unwinding of the double helix by transcribing RNA polymerases would produce a positive torsional stress that could be removed by a topoisomerase activity. Because the yeast RNA polymerase II unwinds 14 bp in vitro (Pedone and Ballario 1984), a decrease in the linking number of five predicts the presence of three to four RNA polymerase molecules transcribing the induced CYC1-lacZ fusion at any given moment. This figure is in line with a rough estimate of the frequency of initiation at the $\mathrm{CYCl}$ promoter, based on estimates of the number of transcripts per cell and the half-life of the message (Zitomer et al. 1979|.

A picture slightly more complicated than the above has emerged from studies on an E. coli plasmid, with or without a functional promoter for the tet gene (Pruss and Drlica 1986). In this case, a transcriptionally induced increase in negative supercoiling was observed only in a strain missing the type I topoisomerase encoded by topA. It has been suggested that the transcribing RNA polymerase generates positive stress ahead of itself and negative stress behind itself, both of which are relaxed by the action of topoisomerases (Liu and Wang 1987). Because the topA product relaxes negative but not positive supercoils, an accumulation of negative supercoils would be in evidence in a topA mutant. Because yeast type I topoisomerases do not show a preference for relaxing positive or negative supercoils, we do not favor this model to explain our results. In addition, the yeast strain employed in our studies has type I topoisomerase activity (B.I. Osborne and L. Guarente, unpubl.).

Previous experiments in yeast showed that transcriptional activation of the silent mating-type loci resulted in a decrease in negative supercoiling (Abraham et al. 1983). We believe that the difference between these results and ours may relate to the specific mechanism operating to repress the silent mating-type genes. This mechanism has been associated with an origin of replication and with substantial changes in chromatin structure at the silent loci (Brand et al. 1987). These additional factors may cloud a change in supercoiling that was specifically associated with transcription.

\section{The role of topoisomerases in transcription}

Previous studies show that transcription by yeast RNA polymerase II can continue in the absence of the TOP1 and TOP2 gene products (Brill et al. 1987). In these experiments, induction of chromosomal GAL genes was monitored after shift of a top1 top $2^{\text {ts }}$ strain to the nonpermissive temperature. One might have concluded from our results that the continued action of topoisomerase would be required for RNA polymerase action. A major difference between our system and the GAL loci studied is that the CYC1-lacZ transcriptional unit re- 
sides on a small, closed circular DNA. It is possible that positive torsional stress generated by transcription in the chromosome is dissipated over a much larger region. Relaxation by topoisomerase, in such a case, might not be necessary. This explanation makes the prediction that CYC1-lacZ transcription in our system, unlike transcription of the chromosomal GAL1 gene, would be sensitive to temperature shift in the top1 top $2^{\text {ts }}$ strain. A second possible explanation is that positive torsional stress is generated in the chromosomal GAL1 gene, as in the plasmid, and is removed by topoisomerase but that this relaxation is not required for the continued transcription of the GAL1 gene. A third possibility is that torsional stress is generated in the chromosome, as in the plasmid, and can be removed by a topoisomerase activity other than that of the TOP1 or TOP2 gene products. An examination of CYC1-lacZ transcription from the plasmid in the top1 top $2^{\text {ts }}$ strain should distinguish among these possibilities.

\section{Implications for yeast $m R N A 3^{\prime}$-end formation}

In higher cells, the formation of mRNA $3^{\prime}$ ends is dictated in part by the AAUAAA RNA cleavage signal and by termination sequences that lie downstream of the signal, as shown by nuclear run-on assays (for review, see Frayne et al. 1984; Wickens and Stephenson 1984; Birnstiel et al. 1985; Falck-Pedersen et al. 1985; Hart et al. 1985). Our results show that the 83-bp fragment at the $3^{\prime}$ end of $C Y C 1$, taken from a region required for the formation of the $3^{\prime}$ end of the CYC1 mRNA (Zaret and Sherman 1982), is capable of $3^{\prime}$-end specification when inserted into the body of a transcribed region. Furthermore, the finding that the fragment-bearing constructs, like the internally deleted construct, exhibited a reduction in negative supercoiling compared with pLG-312 suggests that the fragment halts RNA polymerase. Were the fragment solely an RNA processing signal, effects on supercoiling of the plasmid would not be expected.

\section{Materials and methods}

\section{DNA isolation and Southern blotting}

DNA was isolated by a modified procedure of Abraham et al. (1983). Yeast transformants were grown in $25 \mathrm{ml}$ to an $\mathrm{OD}_{600}$ of 1.0-1.5, washed once with water, and resuspended in $1 \mathrm{ml}$ of $1.2 \mathrm{M}$ sorbitol-10 $\mathrm{mM} \mathrm{CaCl}_{2}-10 \mathrm{mM}$ Tris $-\mathrm{HCl}(\mathrm{pH} 7.3)$ in 1.5$\mathrm{ml}$ plastic microfuge tubes. Twenty five microliters of a 3 $\mathrm{mg} / \mathrm{ml}$ solution of zymolyase 100-T (Seikagaku Kogyo) was added to each tube, and tubes were incubated for $20 \mathrm{~min}$ at $30^{\circ} \mathrm{C}$. Cells were pelleted quickly, supernatants removed, and $200 \mu \mathrm{l}$ of a $10 \%$ SDS $-25 \mathrm{~mm}$ EDTA-0.1 M Tris- $\mathrm{HCl}(\mathrm{pH} 9.0)$ solution was added to each pellet. Tubes were vortexed vigorously and immediately placed in boiling water for $3 \mathrm{~min}$. Tubes were placed on ice, $200 \mu \mathrm{l}$ of $5 \mathrm{~m} \mathrm{~K}$ acetate was added to each, and they were incubated for 30-60 min. Tubes were spun at $10,000 \mathrm{~g}$ for $5 \mathrm{~min}$, supernatants were taken, $200 \mu \mathrm{l}$ of $5 \mathrm{M} \mathrm{NH}_{4}$ acetate was added to each supernatant, and the tubes were filled with 2-propanol. Precipitates were resuspended in TE and extracted twice with phenol-chloroform-isoamyl alcohol (25: $25: 1)$. One-half the final precipitate was used per gel lane.
Gels were run in Tris-phosphate, according to Shure et al. (1977), in $0.5 \%$ agarose with 4 (Fig. 1 only) or $2 \mu \mathrm{g} / \mathrm{ml}$ chloroquine (Sigma). Gel transfer to GeneScreen Plus (New England Nuclear), hybridizations, and washes were done according to the method of K.C. Reed (Bulletin 1234, BioRad Laboratories, Richmond, CA) and Reed and Mann (1985). Northern blotting and RNA preparation were performed as described previously (Schneider and Guarente 1987). The hybridization probe for all experiments extended from the SacI site of CYC1-lacZ to the StuI site of $U R A 3$ from pLG-312. DNA fragments were labeled by the random primer method (Feinberg and Vogelstein 1984).

At least four blots were performed per figure, using DNA from independent transformants, with visually indistinguishable results. Band intensity was assessed by laser densitometry. Differences in supercoiling were determined by comparing the peaks of highest amplitude in each distribution.

\section{Yeast strains, transformation, and media}

BWG1-7a MATa leu2-3, leu2-112 his4-519, ade1-100 ura3-52 was the recipient strain in all experiments /Guarente and Mason 1983). Yeast was transformed by the lithium acetate method and grown in SD synthetic minimal medium with $2 \%$ lactic acid $(\mathrm{pH} 5.0)$ or $2 \%$ glucose, $0.25 \%$ casamino acids, and $0.004 \%$ adenine (Sherman et al. 1986).

\section{Plasmids}

Plasmids LG-669Z, LG-312 (Guarente and Mason 1983), LG-178 (Guarente et al. 1984), and Bal6 (Hahn et al. 1985) have been described. Plasmid BT + B was derived from pLG-312, first by cutting with BamHI and TthIl11, filling in, and religating, making pBT. The BamHI-TthIl11 fragment of pLG-312 was purified along with $X b a I$-cut $\mathrm{pBT}$. The DNAs were filled in with Klenow fragment (Boehringer) and ligated together, so that the TthIl11 site was nearest URA3, making $\mathrm{pBT}+\mathrm{B}$.

The plasmids BI02OC, BI02OU, BI03OC, BI03OU, BI04OC, and BI04OU were derived from pLG-669Z, the parent of pLG-312. The SmaI-SmaI fragment of pLG-669Z was deleted, generating $\mathrm{p} \Delta \mathrm{Sma}$. A SalI 8-mer (New England Biolabs) was ligated into p $\Delta$ Sma cut with BamHI, SacI, or TthIll1 filled in, making BI03O, BI02O, and $\mathrm{BI04O}$, respectively. Addition of the Sall 8-mer at these sites has no effect on transcriptional read through or superhelical density when compared to pLG-312 (data not shown).

The $3^{\prime}$ end of CYC1 was subcloned as follows: The 83-bp AvalI-FnuDII fragment was purified from a digest of $\mathrm{pCYCl}$ (Smith et al. 1979), filled in, and ligated into filled-in SalI, AvaI-cut pBR322. This ligation restores AvaI and Sall in the proper orientation. This intermediate plasmid was cut with AvaI, filled-in, and a XhoI 8-mer (New England Biolabs) was added, making BI02, from which the AvaII-FnuDII fragment can be excised by XhoI, Sall digestion. The Xhol-Sall fragment was ligated into Sall-cut BI02O, BI03O, and BI04O in the CYC1 (C) and UTR1 (U) orientations, making BI02OC, BI02OU, BI03OC, BI03OU, BI04OC, and BI04OU.

\section{Acknowledgments}

We thank A. Varshavsky, P. Schimmel, M. Syvanen, and S. Forsburg for critical reading of the manuscript, and Clea A. Zolotow for help in preparing the manuscript. This work was supported by National Institutes of Health grant 5R0I GM30454-05 to L.G. and Whitaker Health Sciences Fund grant $83-02 R$ to L.G. 


\section{References}

Abraham, J., J. Feldman, K.A. Nasmyth, J.N. Strathern, A.J.S Klar, J.R. Broach, and J.B. Hicks. 1983. Sites required for position-effect regulation of mating-type information in yeast. Cold Spring Harbor Symp. Quant. Biol. 48: 989-995.

Birnstiel, M.-L., M. Busslinger, and K. Strub. 1985. Transcription termination and $3^{\prime}$ processing: The end is in site Cell 41: $349-359$

Brand, A.H., G. Micklem, and K. Nasmyth. 1987. A yeast silencer contains sequences that can promote autonomous plasmid replication and transcriptional activation. Cell 51: 709-719.

Brill, S.J., S. DiNardo, K. Voelkel-Meiman, and R. Sternglanz. 1987. Need for DNA topoisomerase activity as a swivel for DNA replication for transcription of ribosomal DNA. $\mathrm{Na}$ ture 326: 414-416.

Broach, J.R. 1981. The yeast plasmid $2 \mu$ circle. In The molecular biology of the yeast Saccharomyces. Life cycle and in heritance (ed. Strathern et al.), pp. 445-470. Cold Spring Harbor Laboratory, Cold Spring Harbor, New York.

DiNardo, S., K. Voelkel, and R. Sternglanz. 1984. DNA topoisomerase II of Saccharomyces cerevisiae: Topoisomerase II is required for segregation of daughter molecules at the termination of DNA replication. Proc. Natl. Acad. Sci. 81: 26162620.

Falck-Pedersen, E., J. Logan, T. Shenk, and J.E. Darnell. 1985 Transcription termination within the ElA gene of adenovirus induced by insertion of the mouse $\beta$-major globin terminator element. Cell 40: 897-905.

Feinberg, A.P. and B. Vogelstein. 1984. A technique for radiolabelling DNA restriction fragments to high specific activity. Addendum Anal. Biochem. 137: 266-267.

Frayne, E.G., E.J. Leys, G.F. Course, A.G. Hook, and R.E. Kellems. 1984. Transcription of the mouse dihydrofolate reductase gene proceeds unabated through seven polyadenylation sites and terminates near a region of repeated DNA. Mol. Cell. Biol. 4: 2921-2924.

Gamper, H.B. and J.E. Hearst. 1982. A topological model for transcription based on unwinding angle analysis of $E$. coli RNA polymerase binary, initiation and ternary complexes. Cell 29: 81-90.

Gellert, M. 1981. DNA topoisomerases. Annu. Rev. Biochem. 50: $879-910$.

Goto, T. and J.C. Wang. 1984. Yeast DNA topoisomerase II is encoded by a single-copy, essential gene. Cell 36: 10731080.

- 1985. Cloning of yeast TOPI, the gene encoding DNA topoisomerase I, and construction of mutants defective in both DNA topoisomerase I and DNA topoisomerase II. Proc. Natl. Acad. Sci. 82: 7178-7182.

Guarente, L. and T. Mason. 1983. Heme regulates transcription of the CYC1 gene of Saccharomyces cerevisiae via an upstream activation site. Cell 32: 1279-1286.

Guarente, L., B. Lalonde, P. Gifford, and E. Alani. 1984. Distinctly regulated tandem upstream activation sites mediate catabolite repression of the CYC1 gene of Saccharomyces cerevisiae. Cell 36: 503-511.

Hahn, S., E. Hoar, and L. Guarente. 1985. Each of three 'TATA elements' specifies a subset of the transcription initiation sites at the CYC1 promoter of Saccharomyces cerevisiae. Proc. Natl. Acad. Sci. 82: 8562-8566.

Hart, R.P., M.A. McDevitt, and J.R. Nevins. 1985. Poly(A) site cleavage in a HeLa nuclear extract is dependent on downstream sequences. Cell 43: 677-683.

Holm, C., T. Goto, J.C. Wang, and D. Botstein. 1985. DNA to- poisomerase II is required at the time of mitosis in yeast. Cell 41: 553-563.

Liu, L.F. and J.C. Wang. 1987. Supercoiling of the DNA template during transcription. Proc. Natl. Acad. Sci. 84: 70247027.

Pedone, F. and P. Ballario. 1984. Stimulation of yeast RNA polymerase II transcription by critical values of supercoiling. Biochemistry 23: 69-76.

Pruss, G.J. and K. Drlica. 1986. Topoisomerase I mutants: The gene on pBR322 that encodes resistance to tetracycline affects plasmid DNA supercoiling. Proc. Natl. Acad. Sci. 83: 8952-8956.

Reed, K.C. and D.A. Mann. 1985. Rapid transfer of DNA from agarose gels to nylon membranes. Nucleic Acids Res. 13: $7207-7221$.

Schneider, J.C. and L. Guarente. 1987. The untranslated leader of the nuclear COX4 gene of Saccharomyces cerevisiae contains an intron. Nucleic Acids Res. 15: 3515-3529.

Sherman, F., G.R. Fink, and J.B. Hicks. 1986. Laboratory course manual for methods in yeast genetics. Cold Spring Harbor Laboratory, Cold Spring Harbor, New York.

Shure, M., D.E. Pulleyblank, and J. Vinograd. 1977. The problems of eukaryotic and prokaryotic DNA packaging and in vivo conformation posed by superhelix density heterogeneity. Nucleic Acids Res. 4: 1183-1205.

Smith, M., D.W. Leung, S. Gillam, C.R. Astell, D.L. Montgomery, and B.D. Hall. 1979. Sequence of the gene for iso-1 cytochrome $c$ in Saccharomyces cerevisiae. Cell 16: 753761.

Sternglanz, R., S. DiNardo, K.A. Voelkel, Y. Nishimura, Y. Hirota, K. Becherer, L. Zumstein, and J.C. Wang. 1981. Mutations in the gene coding for Escherichia coli DNA topoisomerase I affect transcription and transposition. Proc. Natl. Acad. Sci. 78: 2747-2750.

Thrash, C., A.T. Bankier, B.G. Barrell, and R. Sternglanz. 1985. Cloning, characterization, and sequence of the yeast DNA topoisomerase I gene. Proc. Natl. Acad. Sci. 82: 4374-4378.

Uemura, T. and M. Yanagida. 1986. Mitotic spindle pulls but fails to separate chromosomes in type II DNA topoisomerase mutants: Uncoordinated mitosis. $E M B O$ J. 5: $1003-$ 1010.

Wang, J.C. 1985. DNA topoisomerases. Annu. Rev. Biochem. 54: $665-697$

Wang, I.C., J.H. Jacobsen, and J.-M. Saucier. 1977. Physiochemical studies on interactions between DNA and RNA polymerase. Unwinding of the DNA helix by Escherichia coli RNA polymerase. Nucleic Acids Res. 4: 1225-1241.

Wickens, M. and P. Stephenson. 1984. Role of the conserved AAUAAA sequence: Four AAUAAA point mutations prevent messenger RNA 3' end formation. Science 226: 10451051.

Zaret, K.S. and F. Sherman. 1982. DNA sequence required for efficient transcription termination in yeast. Cell 28: 563 573.

Zitomer, R.S., D.L. Montgomery, D.L. Nichols, and B.D. Hall. 1979. Transcriptional regulation of the yeast cytochrome $c$ gene. Proc. Natl. Acad. Sci. 76: 3627-3631. 


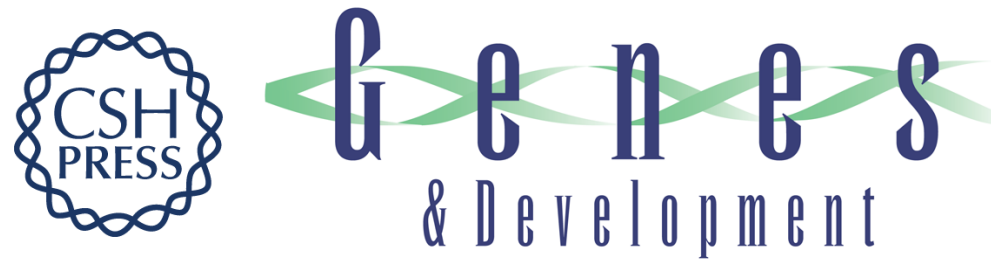

\section{Transcription by RNA polymerase II induces changes of DNA topology in yeast.}

B I Osborne and L Guarente

Genes Dev. 1988, 2:

Access the most recent version at doi:10.1101/gad.2.6.766

References This article cites 32 articles, 10 of which can be accessed free at:

http://genesdev.cshlp.org/content/2/6/766.full.html\#ref-list-1

License

Email Alerting

Service

Receive free email alerts when new articles cite this article - sign up in the box at the top right corner of the article or click here.

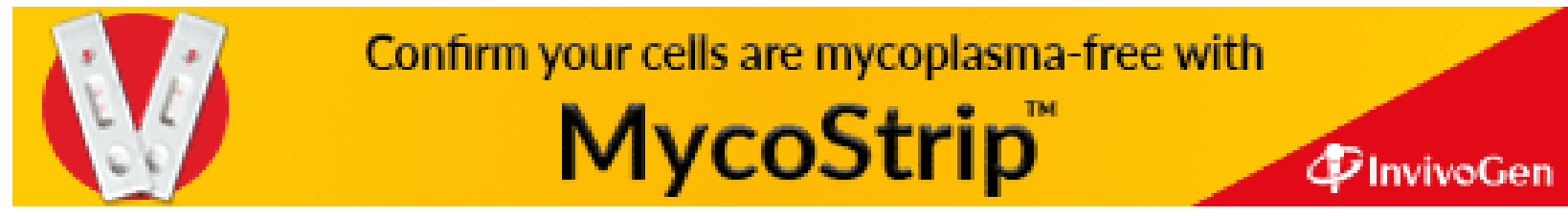

